\title{
Retraction
}

The article titled, "Comparative study between proximal femoral nail and dynamic hip screw with trochanteric stabilizing plate in unstable intertrochantric femur fractures", published in the International Journal of Research in Orthopaedics, Volume 3, Issue 5, 2017, Pages 936-943, DOI: http://dx.doi.org/10.18203/issn.24554510.IntJResOrthop20173198 is being retracted. After the publication of the above article, one of the researchers reported that a large part of the text, clinical photographs, $\mathrm{x}$-ray images and tables are plagiarized from his dissertation work. We contacted the author who could not satisfactorily respond to our queries. Since the author could not satisfactorily defend his paper, it was decided to retract the article from International Journal of Research in Orthopaedics. 


\title{
Original Research Article
}

\section{Comparative study between proximal femoral nail and dynamic hip screw with trochanteric stabilizing plate in unstable intertrochantric femur fractures}

\author{
Siddaram N. Patil, Pandurangaiah Srinivas*
}

Department of Orthopaedics, Sri Devaraj Urs Medical College, Kolar, Karnataka, India

Received: 26 June 2017

Revised: 10 July 2017

Accepted: 12 July 2017

\author{
*Correspondence: \\ Dr. Pandurangaiah Srinivas, \\ E-mail: srinivas_pandurangaiah@rediffmail.com
}

Copyright: (c) the author(s), publisher and licensee Medip Academy. This is an open-access article distributed under the terms of the Creative Commons Attribution Non-Commercial License, which permits unrestricted non-commercial use, distribution, and reproduction in any medium, provided the original work is properly cited.

\section{ABSTRACT}

Background: Unstable fractures accounts for approximately 50 to $60 \%$ of all intertrochanteric fractures. Failure rates of (DHS) dynamic hip screw for unstable fracture patterns are as high as $50 \%$. Proximal femoral nail is technically more demanding surgery and also associated with complications like implant failure, femoral shaft fracture, improper reduction, screw cut-out and non-union. This study was done to compare the results of using Trochanteric stabilization plate in addition to dynamic hip screw versus proximal femoral nail which is considered as a better implant for unstable fractures.

Methods: A prospective study was conducted comparing outcomes of proximal femoral nailing versus trochanteric stabilization plate with dynamic hip screw for 44 patients with unstable intertrochanteric fractures (22 each). Harris hip scoring system and Parker mobility score was used for evaluation.

Results: In our study, Average time of union in all 22 patients of PFN group was about 12 weeks while average time of union in all 22 patients of DHS with TSP group was about 14 weeks. The Harris hip score was 85.45 in DHS with TSP group while it was 84.72 in the PFN group ( $\mathrm{p}=0.846$ ). The Parker mobility score was 7.81 in the DHS with TSP group while it was 7.95 in the PFN group $(\mathrm{p}=0.728)$.

Conclusions: Use of TSP with DHS can give good results in unstable IT fractures. Addition of TSP to DHS gives good lateral wall buttress which prevent excessive medialisation of shaft and gives comparable result to PFN.

Keywords: Unstable intertrochanteric fractures, Trochanteric stabilization plate, Dynamic Hip screw, Proximal femoral nailing

\section{INTRODUCTION}

Intertrochanteric fractures are defined as fractures involving upper end of femur through and in between both trochanters with or without extension into upper femoral shaft. ${ }^{1}$ In 1990, 26\% of all hip fractures occurred in Asia whereas this figure could rise to $37 \%$ in 2025 and $45 \%$ in $2050.2,3$ Stable fractures are those which are undisplaced and with intact posteromedial cortex. ${ }^{4}$
Unstable fractures accounts for approximately 50 to $60 \%$ of all intertrochanteric fractures. ${ }^{5,6}$ These fractures remain a problem, particularly in patients who do not restrain from full weight bearing during early mobilization. ${ }^{7}$ Kaufer described five variables that affect the biomechanical strength of repair. Surgeon independent variables are bone quality, which is related to age and osteoporosis, fracture pattern or fracture stability, which must be understood and will affect the variables that are surgeon dependent. Surgeon dependent variables are 
implant choice, quality of fracture reduction, and positioning of the implant. ${ }^{8}$ Failure rates of (DHS) dynamic hip screw for unstable fracture patterns are as high as $50 \% \%^{9,10}$ whereas in stable fractures it is around $5 \%$. Buttress plates i.e., trochanter stabilizing plate act as an adjunct to sliding screw plate devices and aim to restore the lacking lateral buttress. Encouraging results have been reported by several groups ${ }^{7,11,12}$ using a trochanter stabilising plate in small series. PFN is technically more demanding surgery and also associated with complications like implant failure, femoral shaft fracture, improper reduction, screw cut-out and nonunion. This study was done to compare the results of using TSP in addition to DHS to see whether this augmentation gives better results and reduces the complication rate as compared to using DHS alone. We compared these group of patients with fixation using PFN which is considered as a better implant for unstable fractures.

\section{METHODS}

A prospective study was conducted from December 2013 to December 2015 comparing the results and outcomes of Proximal femoral nailing versus Trochanteric stabilization plate with Dynamic hip screw for 50 patients with unstable intertrochanteric fractures (25 each). Inclusion criteria were Patients with fracture as A2.2 and onward, classified using AO classification, patients with age 18 years and more. Exclusion criteria were open fractures, previous fractures or surgery in affected hip. All the recruited patients were examined clinically after history taking, necessary investigations and X-rays were done. X-rays of the pelvis with both hips - AP view, Xray of the affected hip - AP and lateral view, chest X-ray - PA view was done. The patients were operated after optimization of their medical conditions. The following points were noted: 1 . Parker's mobility score and Harris hip score. 2. Duration from trauma to surgery was noted. 3. Intraoperative findings like type of anaesthesia, type of reduction, duration of the surgery, blood loss $(\mathrm{ml})$ and no. of c-arm shoots. 4. Radiologically patient was evaluated for alignment and displacement. The figure of the PFN used for our patients is shown in Figure 1.

The trochanteric stabilizing plate was an adjunct to compression hip screw fixation. It prevents excessive collapse and medial translation of the shaft. ${ }^{6}$

It was a low profile plate and had a leaf like shape for greater trochanter and 1 hole distally which matches with 1 st cortical screw of DHS plate.

\section{Surgical techniques}

$P F N$ : The patient was placed in supine position on fracture table with adduction of the affected limb by $10^{0}$ to $15^{\circ}$ and closed reduction of the fracture was done by traction and gentle rotation. $5 \mathrm{cms}$ longitudinal incision was taken proximally from the tip of the greater trochanter. A parallel incision was made in the fascia lata and gluteus medius was split in line with the fibres. Tip of the greater trochanter was exposed. In AP view on Carm, the entry point was on the tip or slightly lateral to the tip of the greater trochanter. Entry was done with an awl. Guide wire passed through the fracture with image guidance to the shaft of femur. Reaming was done over the guide wire. The appropriate sized PFN nail was inserted without hammering preferably. Then both the neck screw (central screw) and the hip screw (antirotation screw) (proximal) were inserted into the head of the femur. Then distal locking was done usually with two screws. Image guidance was used wherever necessary.

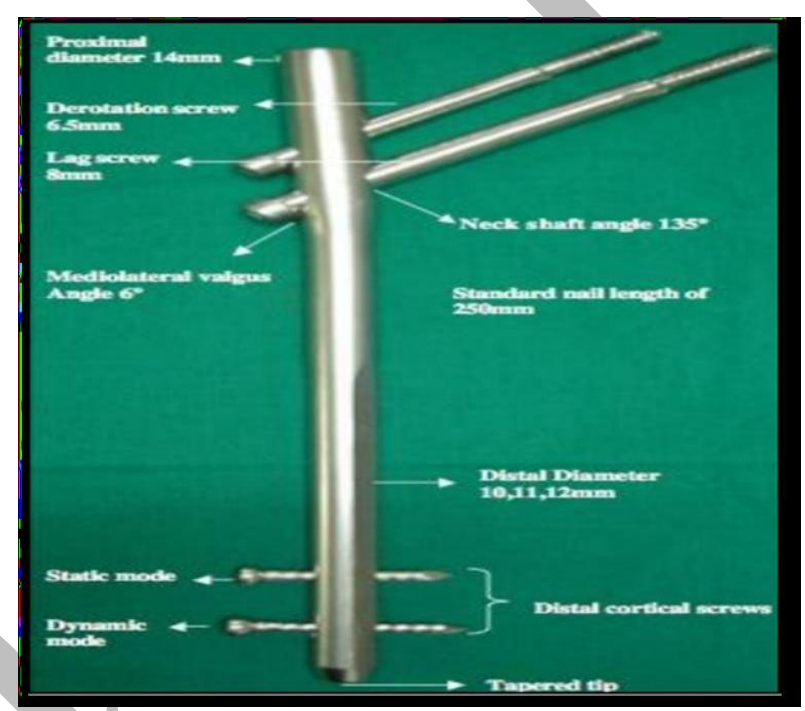

Figure 1: Shows the proximal femoral nail.

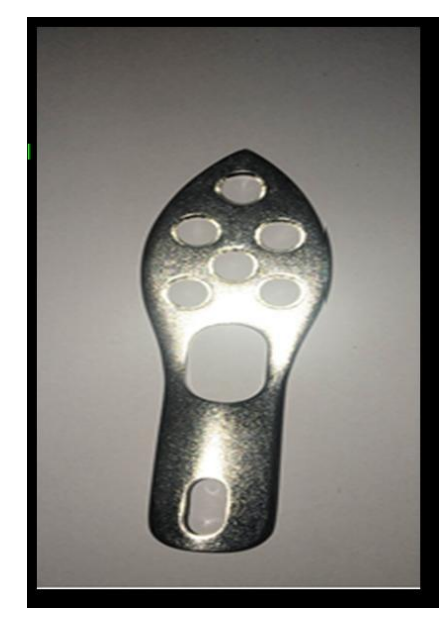

Figure 2: Shows the trochanteric stabilization plate.

DHS with TSP: Position of the patient was same as above. The vastus lateralis splitting approach was used. The greater trochanter and upper part of shaft of femur was exposed. A guide wire was passed 1 inch below the base of the greater trochanter into the centre of the femoral head under $\mathrm{C}$-arm image guidance in both AP and lateral views. Triple reaming was done. DHS screw was inserted. TSP was placed inside the sliding plate and under fluoroscopic guidance contouring of TSP done 
according to the shape of greater trochanter. The 1st cortical screw fixed DHS plate with TSP with shaft of femur thus stabilising DHS with TSP. A 6.5-mm screw was passed parallel to the DHS through the TSP to act as an antirotation screw while permitting sliding collapse. Greater trochanter was fixed with $6.5 \mathrm{~mm}$ or $4.0 \mathrm{~mm} \mathrm{CC}$ screw.

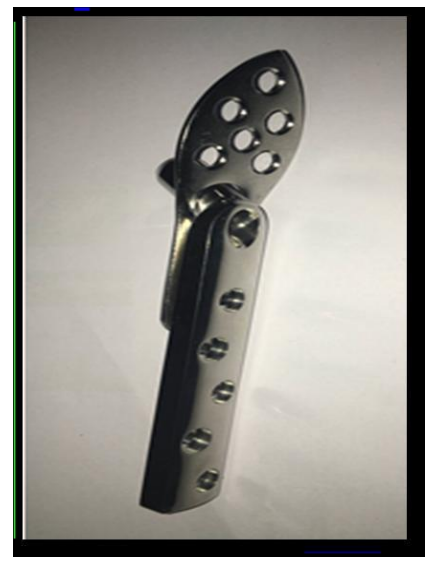

Figure 3: Shows the trochanteric stabilization plate with dynamic hip Screw.

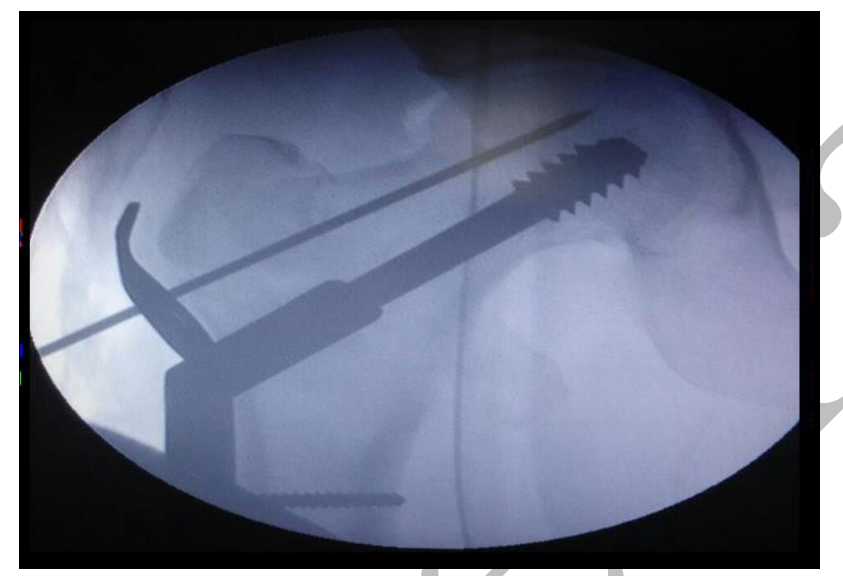

Figure 4: Shows the Carm image of TSP with DHS.

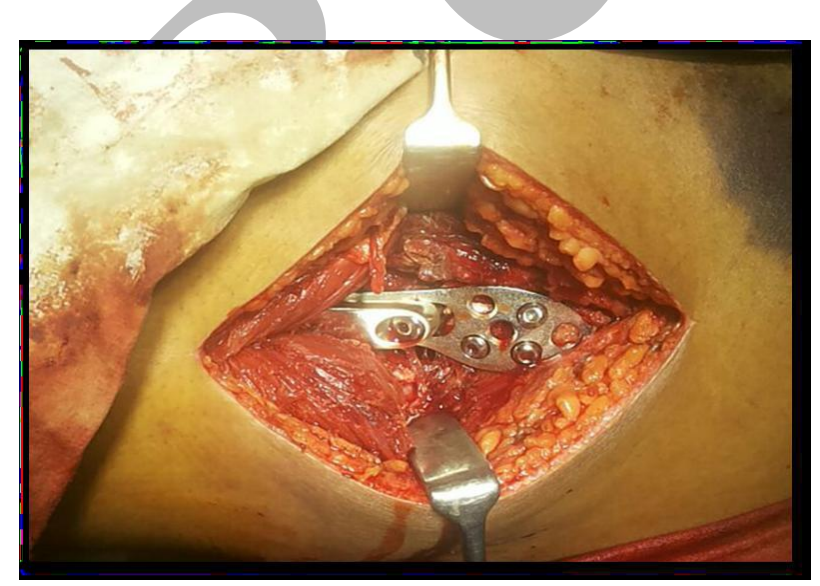

Figure 5: Shows the intraoperative clinical photo of TSP with DHS.
Patients were encouraged to sit in the bed after 24 hours after surgery. Patients were taught quadriceps setting exercises, ankle pumps and knee mobilization in the immediate postoperative period. Patients were taught gait training before discharge from the hospital. Patients were encouraged to weight bear partially with axillary crutches or walker depending on the pain tolerability of individual patient from 3rd day. Patients were discharged from the hospital when independent walking was possible with walking aids mostly on 4th day. Patients were followed up at 2 weeks, 1.5 months, 3 months, 4.5 months and 6 months. At every visit patient was assessed clinically regarding hip and knee function, walking ability, fracture union and deformity.

Harris hip scoring system and Parker mobility score was used for evaluation. X-ray of the involved hip with femur was done to assess: 1. Signs of union. 2. Neck - shaft angle. 3. Failure of fixation. 4. Failure of implant.

\section{Parker mobility score}

Assessment of mobility before the fracture. Score is the total - 0 to 9 .

Table 1: Parker mobility score.

\begin{tabular}{|lllll|}
\hline Mobility & $\begin{array}{l}\text { No } \\
\text { difficulty }\end{array}$ & $\begin{array}{l}\text { With } \\
\text { an } \\
\text { aid }\end{array}$ & $\begin{array}{l}\text { With help } \\
\text { from another } \\
\text { person }\end{array}$ & $\begin{array}{l}\text { Not } \\
\text { at } \\
\text { all }\end{array}$ \\
\hline $\begin{array}{l}\text { Able to } \\
\text { get about } \\
\text { the house }\end{array}$ & 3 & 2 & 1 & 0 \\
\hline $\begin{array}{l}\text { Able to } \\
\text { get out of } \\
\text { the house }\end{array}$ & 3 & 2 & 1 & 0 \\
\hline $\begin{array}{l}\text { Able to } \\
\text { go } \\
\text { shopping }\end{array}$ & 3 & 2 & 1 & 0 \\
\hline
\end{tabular}

\section{Harris hip score scale}

Table 2: Shows the Harris hip score scale rating.

\begin{tabular}{|l|l|}
\hline Score & Rating \\
\hline $\mathbf{9 0 - 1 0 0}$ & Excellent \\
\hline $\mathbf{8 0 - 8 9}$ & Good \\
\hline $\mathbf{7 0 - 7 9}$ & Fair \\
\hline $\mathbf{6 0 - 6 9}$ & Poor \\
\hline
\end{tabular}

\section{Statistical analysis}

Analyses were performed using IBM SPSS version 22 software (SPSS Inc, Chicago, IL). Coded data were entered into an excel sheet. Outcome measures were presented by Mean, SD, Proportions and confidence intervals. Comparison of quantitative measures was done by $t$ test and difference in proportions by Chi-square test. $\mathrm{P} \leq 0.05$ was considered as statistically significant. 


\section{RESULTS}

25 patients were treated with TSP + DHS and 25 patients were treated with PFN. Three from each group i.e., Six patients could not be followed up and were excluded. The average age of patients in our study was 61.05 years with range from 32 - 90 years with most patients belong to 60 to 69 years of age. In our study no. of male patients $(n=26)$ were significantly more than female patients $(n=18)$. In our study, mode of trauma was significantly more due to trivial fall $(\mathrm{n}=27)$ than Road Traffic Accident $(n=17) .66 \%$ had left sided injury and $34 \%$ had right sided injury.

Table 3: Shows the results of type of fracture.

\begin{tabular}{|llll|}
\hline Type of fracture & PFN & DHS with TSP & Total \\
\hline Type A 2.2 & 5 & 8 & 13 \\
\hline Type A 2.3 & 12 & 13 & 25 \\
\hline Type A 3.1 & 4 & 1 & 5 \\
\hline Type A 3.2 & 1 & 0 & 1 \\
\hline Total & 22 & 22 & 44 \\
\hline
\end{tabular}

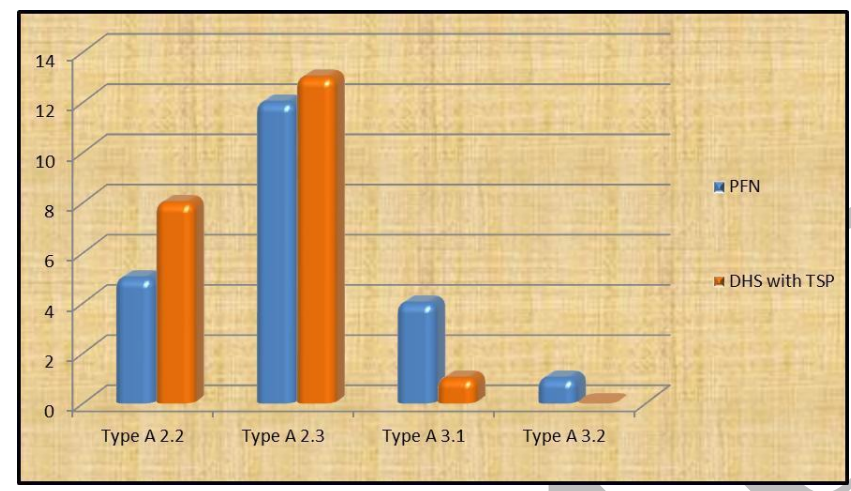

Figure 6: shows the results of Type of fracture graphically.

Table 4: Shows the time duration from trauma to surgery.

\begin{tabular}{|llll|}
\hline Time duration (days) & PFN & $\begin{array}{l}\text { DHS with } \\
\text { TSP }\end{array}$ & Total \\
\hline $\mathbf{1 - 5}$ & 3 & 3 & 6 \\
\hline $\mathbf{6 - 1 0}$ & 8 & 10 & 18 \\
\hline $\mathbf{1 1 - 1 5}$ & 4 & 6 & 10 \\
\hline $\mathbf{1 5 - 2 0}$ & 7 & 3 & 10 \\
\hline
\end{tabular}

Table 5: Shows the Harris hip score.

\begin{tabular}{|llll|}
\hline $\begin{array}{l}\text { Harris hip score } \\
\text { (follow up) }\end{array}$ & PFN & $\begin{array}{l}\text { DHS } \\
\text { with TSP }\end{array}$ & $\begin{array}{l}\text { Level of } \\
\text { significance }\end{array}$ \\
\hline HHS 15 days & 17.54 & 16.22 & $\mathrm{P}=0.061$ \\
\hline HHS 1.5 M & 33.86 & 31.86 & $\mathrm{P}=0.061$ \\
\hline HHS 3 M & 61.18 & 60.04 & $\mathrm{P}=0.127$ \\
\hline HHS 4.5 M & 72.13 & 71.45 & $\mathrm{P}=0.573$ \\
\hline HHS 6 M & 84.72 & 85.45 & $\mathrm{P}=0.846$ \\
\hline
\end{tabular}

In our study, we found no statistically significant difference between Harris hip score in both the groups at 15 days, $1.5 \mathrm{~m}, 3 \mathrm{~m}, 4.5 \mathrm{~m}$ and $6 \mathrm{~m}$ follow up (p value $>0.05$ ). Most of the patients were in good and excellent categories as seen in Figure 8.

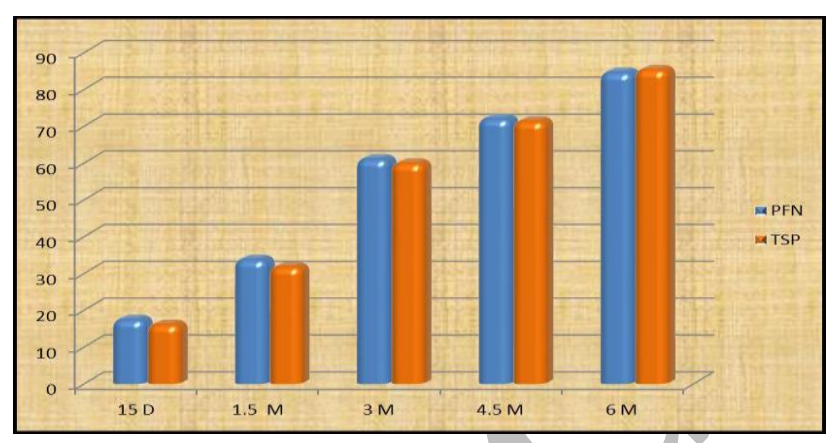

Figure 7: shows the Harris hip score in all the follow up visits.

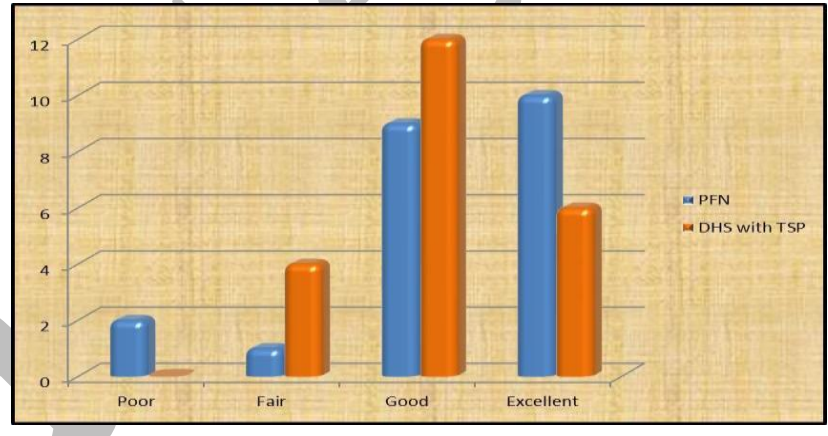

Figure 8: Shows outcome results as per Harris hip score.

Table 6: Shows the Parker mobility score.

\begin{tabular}{|llll|}
\hline $\begin{array}{l}\text { Parker mobility } \\
\text { score (follow } \\
\text { up) }\end{array}$ & PFN & $\begin{array}{l}\text { DHS with } \\
\text { TSP }\end{array}$ & $\begin{array}{l}\text { Level of } \\
\text { significance }\end{array}$ \\
\hline PMS 15 days & 1.36 & 1.36 & $\mathrm{p}=0.757$ \\
\hline PMS 1.5 M & 4.45 & 4.54 & $\mathrm{p}=0.671$ \\
\hline PMS 3 M & 6.18 & 6.27 & $\mathrm{p}=0.677$ \\
\hline PMS 4.5 M & 7.31 & 7.22 & $\mathrm{p}=0.707$ \\
\hline PMS 6 M & 7.95 & 7.81 & $\mathrm{p}=0.728$ \\
\hline
\end{tabular}

In our study, we found no statistically significant difference between Parker mobility score in both the groups at 15 day, 1.5 month, 3 month, 4.5 month and 6 month follow up $(\mathrm{p}>0.05)$.

Table 7: Shows intraoperative parameters.

\begin{tabular}{|llll|}
\hline Parameters & PFN & $\begin{array}{l}\text { DHS with } \\
\text { TSP }\end{array}$ & Significance \\
\hline Blood loss (ml) & 115 & 131.8 & $\mathrm{p}=0.075$ \\
\hline $\begin{array}{l}\text { Intraoperative } \\
\text { time (min) }\end{array}$ & 94.09 & 104.54 & $\mathrm{P}=0.186$ \\
\hline No of shoots & 54.6 & 46.81 & $\mathrm{P}=0.061$ \\
\hline
\end{tabular}




\section{Union rate}

In our study, Average time of union in all 22 patients of PFN group was about 12 weeks (Range: 6 to 16 weeks) while average time of union in all 22 patients of DHS with TSP group was about 14 weeks (Range: 6 to 20 weeks).

Table 8: Shows the complications of TSP and PFN.

\begin{tabular}{|lll|}
\hline Parameters & DHS with TSP (\%) & PFN (\%) \\
\hline $\begin{array}{l}\text { Infection } \\
\text { (superficial) }\end{array}$ & $1(4.5)$ & 0 \\
\hline Infection (deep) & 0 & 0 \\
\hline Non union & 0 & $2(9)$ \\
\hline Implant failure & 0 & $1(4.5)$ \\
\hline Revision surgery & $1(4.5)$ & 0 \\
\hline Screw migration & 0 & $2(9)$ \\
\hline $\begin{array}{l}\text { Periprosthetic } \\
\text { fracture }\end{array}$ & 0 & $2(9)$ \\
\hline
\end{tabular}

\section{Intraoperative complications in PFN}

There was no failure to achieve closed reduction among all 25 patients. There was no iatrogenic fracture of lateral cortex among all 25 patients. There were no instances of drill bit breakage or jamming of nail. In two cases, Iatrogenic fracture occurred while distal locking. There was excessive valgus angulation in 3 out of 22 patients.

\section{Intraoperative complications in DHS with TSP}

There was no failure to achieve closed reduction among all 25 patients. There was no iatrogenic fracture of lateral cortex among all 25 patients. There was excessive valgus angulation in 4 of 22 patients.

There was only one case of superficial infection in DHS with TSP group which was treated on OPD basis with oral antibiotics and did not required implant removal or debridement. No case of Deep infection in both the groups. Implant breakage occurred in one patient of PFN group $(4.54 \%)$ who was not willing for further treatment and got united in malposition. No patient of DHS with TSP group developed implant failure. Two patients developed reverse Z-effect in PFN group of which 1 patient underwent implant removal and was not willing for further management so discharged on skin traction. $2^{\text {nd }}$ patient was lost to follow up. No patient of DHS with TSP group developed screw cut-out. In DHS with TSP group, 1 patient required revision in immediate post op period as reduction was not acceptable. No patient of PFN group required revision surgery.

Two patients of PFN group developed Periprosthetic fracture intraoperatively while doing distal locking. So encirclage wiring was done in those cases as Long PFN was not available intraoperatively. Patients were monitored over a period of time and eventually fracture healed well.

Table 9: Shows about shortening.

\begin{tabular}{|lll|}
\hline Shortening & PFN & DHS with TSP \\
\hline $\mathbf{1} \mathbf{~ c m ~}$ & 4 & 7 \\
\hline $\mathbf{1}$ to $\mathbf{2} \mathbf{~ c m}$ & 0 & 2 \\
\hline$>\mathbf{2} \mathbf{~ c m}$ & 0 & 0 \\
\hline
\end{tabular}
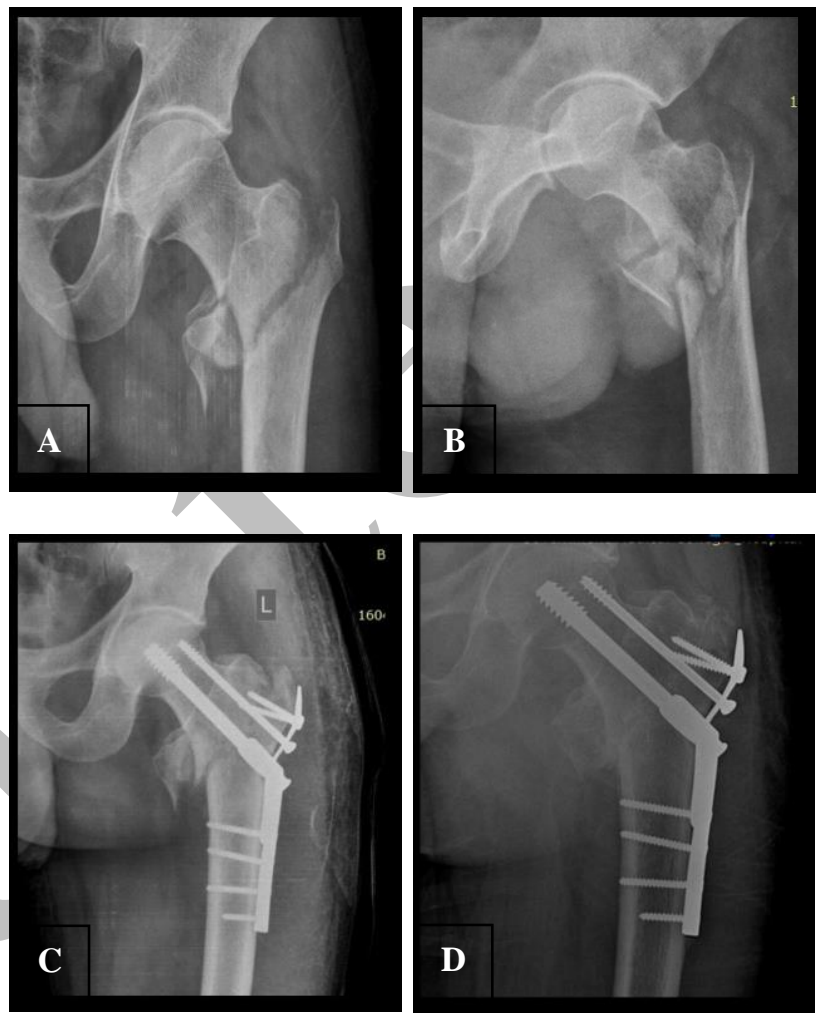

Figure 9: (A) Shows the AP view of preop X-ray of patient A; (B) Shows the lateral view of preop X-ray of patient A; (C) Shows the AP view of the 3 months follow up X-ray of patient A; (D) Shows the X-ray at 6 months showing union of patient $A$.
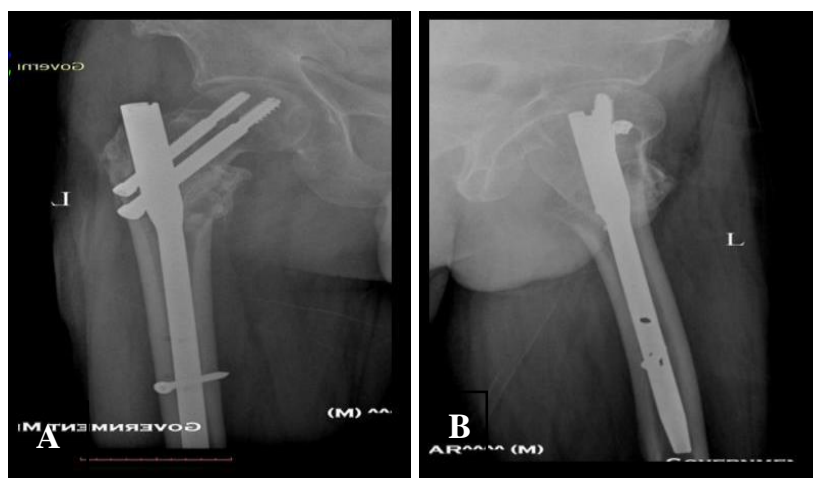

Figure 10: (A) Showing the AP view of patient B with union at 6 months; (B) Showing lateral view of patient $B$ at 6 months with union. 


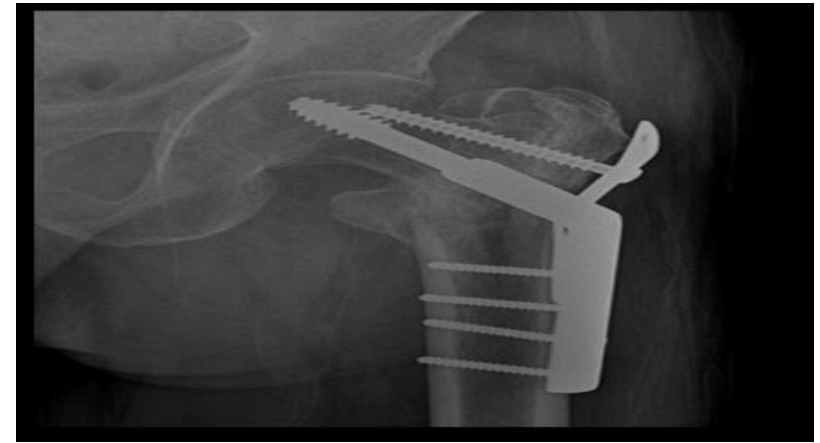

Figure 11: Shows union in patient $C$ at 6 months follow-up.

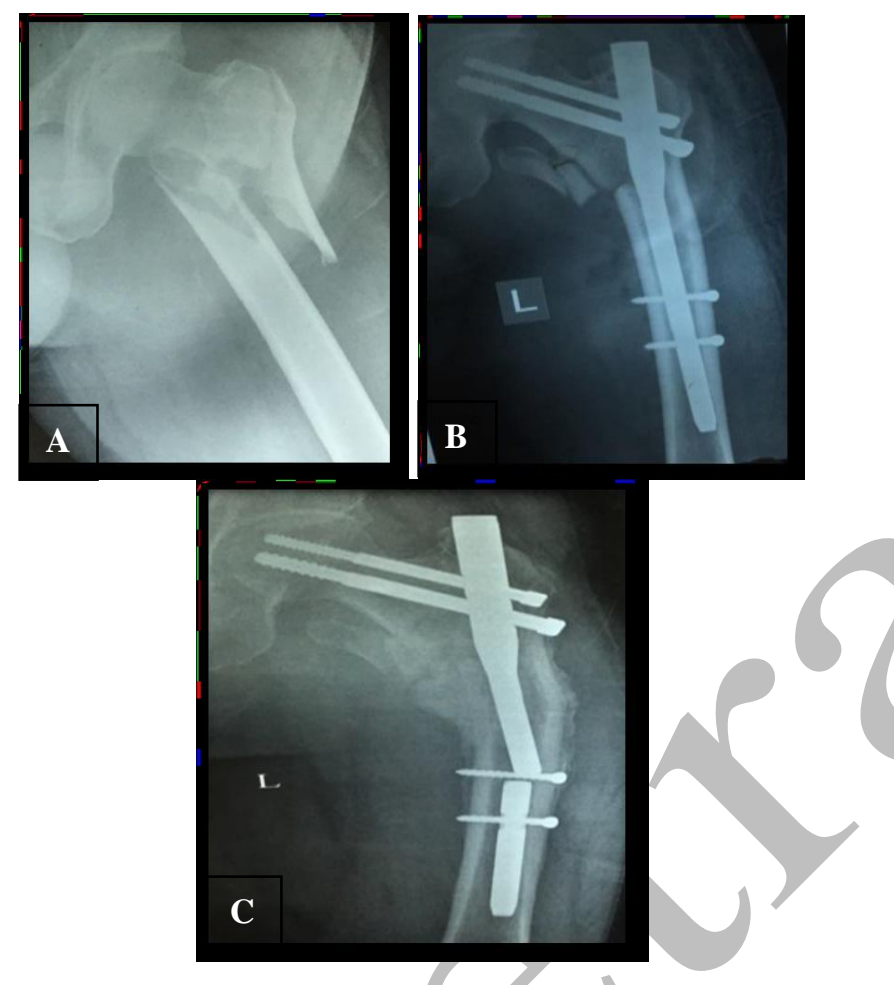

Figure 12: (A) Showing the pre op X-ray of patient D in AP view; (B) Showing the postop X-ray of patient $D$ in AP view; $(C)$ Showing $X$-ray of patient $D$, with

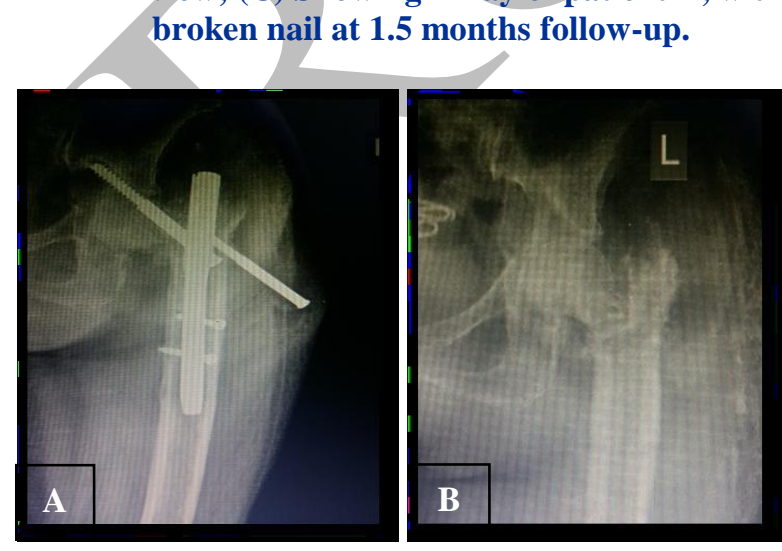

Figure 13: (A) Showing screw backout of patient $\mathbf{E}$ at 6 months follow-up; (B) Shows the X-ray of the patient $\mathrm{E}$ after implant removal.

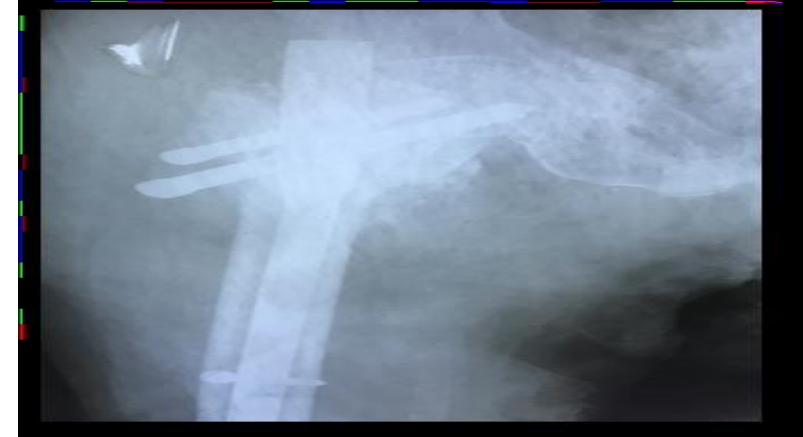

Figure 14: Showing X-ray of patient $F$ with varus collapse at 6 months follow-up.

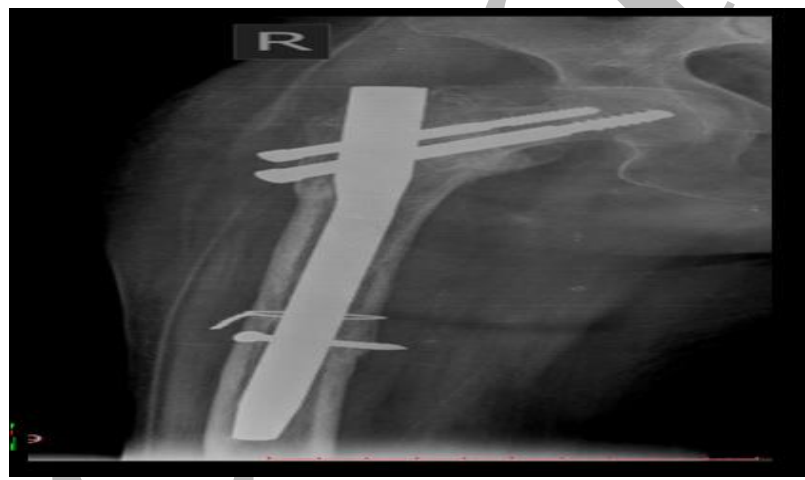

Figure 15: Showing X-ray of patient $G$ at 6 months follow-up with union.
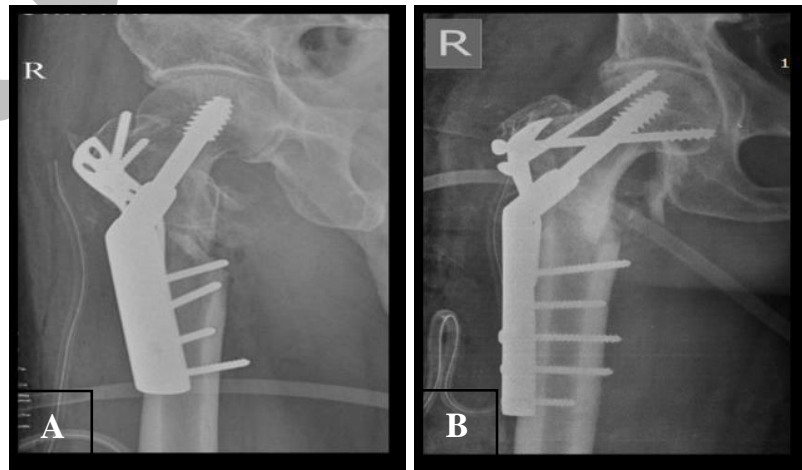

Figure 16: (A) Showing immediate postop X-ray of patient H; (B) Showing postop X-ray of patient $H$ after revision surgery.

\section{DISCUSSION}

Union was seen in all fractures in DHS with TSP group while 2 patients of PFN group went into non-union with screw migration and 1 fracture with implant failure united in malposition. Rho et al in their study found union rate of 18 weeks in PFN group while union rate of 19 weeks in DHS with TSP group compared to12 weeks and 14 weeks in our study respectively. ${ }^{13}$

In DHS with TSP group, Harris hip score at 15 days was 16.22 which is less than PFN group (avg - 17.54). At 1.5 month follow up PFN group had HHS (avg - 33.86) more 
than DHS with TSP group (avg - 31.86). At 3 month also PFN group had HHS (avg - 61.18) more than DHS with TSP group (avg - 60.04). At 4.5 month PFN had HHS (avg - 72.13) more than DHS with TSP group (avg $71.45)$. But at 6 month HHS of DHS with TSP group (avg - 85.45) was more than PFN group (avg - 84.72) because of more complications occurred in PFN group compared to DHS with TSP group. Statistically there was no significant difference between HHS of both the groups at every follow up i.e. 15 days, 1.5 months, 3 months, 4.5 months and 6 months. Result in our study was comparable to Shetty et al study which showed 10 cases of excellent, 10 cases of good, 9 cases of fair and 4 cases of poor result in DHS with TSP group. ${ }^{14}$ While in our study we got 6 cases with excellent, 12 cases with good and 4 cases with fair result with no case of poor result.

Parker mobility score was also used to assess the functional status of patient at follow up. ${ }^{15}$ In DHS with TSP group PMS at 15 days was 1.36 which was equal to PFN group. At 1.5 month follow PFN group had PMS (avg - 4.45) less than DHS with TSP group (avg - 4.54). At 3 month also PFN group had PMS (avg - 6.18) less than DHS with TSP group (avg - 6.27). At 4.5 month PFN had PMS (avg - 7.31) more than DHS with TSP group (avg - 7.22). But at 6 months PMS of DHS with TSP group (avg - 7.81) was more than PFN group (avg 7.95). Still statistically there was no significant difference between PMS of both the groups at every follow up i.e. 15 days, 1.5 months, 3 months, 4.5 months and 6months, which showed that functional outcomes in our study were comparable. The results of our study was comparable with Rho et al study which showed no significant difference between PFN and DHS with TSP group at 6 month follow up. ${ }^{13}$

Table 10: Shows infection rates of various studies, which is comparable to our study

\begin{tabular}{|c|c|}
\hline Name of worker & Infection (\%) \\
\hline Our Study & 2.27 \\
\hline Cyril Jonnes et al $^{16}$ & 3.33 \\
\hline Ranjeetesh Kumar et al ${ }^{1}$ & 4 \\
\hline Kjell Matre et al ${ }^{17}$ & 0.7 \\
\hline RK Gupta et al ${ }^{18}$ & 1.25 \\
\hline Ujjal Bhakat et al ${ }^{19}$ & 3.33 \\
\hline
\end{tabular}

In our study we found 2 patients of DHS with TSP group with shortening of 1 to $2 \mathrm{~cm}$ and had difficulty while walking. So Shoe raise was given in these cases to compensate the shortening. Patients did not have any difficulty later while walking. 7 patients of DHS with TSP group had shortening of $1 \mathrm{~cm}$ and had no difficulty while walking. In PFN group we found 4 patients with shortening of $1 \mathrm{~cm}$ with no difficulty while walking. So we found that TSP overall reduces the chances of limb shortening in unstable cases when used with DHS and gave comparable result to PFN.

\section{CONCLUSION}

Use of TSP with DHS can give good results in unstable IT fractures. As compared to DHS with TSP, PFN is technically more demanding surgery and in our study we found complication rate of PFN to be higher as compared to DHS with TSP. Addition of TSP to DHS gives good lateral wall buttress which prevent excessive medialisation of shaft and gives comparable result to PFN which is considered as better implant in unstable fractures.

\section{Funding: No funding sources} Conflict of interest: None declared

Ethical approval: The study was approved by the institutional ethics committee

\section{REFERENCES}

1. Kumar R, Singh RN, Singh BN. Comparative prospective study of proximal femoral nail and dynamic hip screw in treatment of intertrochanteric fracture femur. J Clin Orthop Trauma. 2012;3(1):28-36.

2. Gullberg B, Johnell O, Kanis JA. World Wide Projection for Hip Fracture. Osteoporosis Int. 1997;7(5):407-13.

3. Melton LJ, Kearns AE, Atkinson EJ, Bolander ME, Achenbach SJ, Huddleston JM, et al. Secular Trends in Hip Fracture Incidence and Recurrence. Osteoporosis Int. 2009;20(5):687- 94.

4. Kyle RF, Gustilo RB, Premer RF. Analysis of six hundred and twenty-two intertrochanteric hip fractures. J Bone Joint Surg Am. 1979;61:216-21.

5. Baumgaertner MR, Curtin SL, Lindskog DM, Keggi JM. The value of the tip apex distance in predicting failure of fixation of peritrochanteric fractures of the hip. J Bone Joint Surg Am. 1995;77:1058-64.

6. Lindskog DM, Michael RB. Unstable Intertrochanteric Hip Fractures in the Elderly. J Am Acad Orthop Surg. 2004;12:179-90.

7. Babst R, Martinet O, Renner N, Rosso R, Bodoky A, Heberer M, et al. Die DHS-Abstützplattefür dieVersorgung der instabilenproximalen Femurfrakturen. Schweizer MedWochenschr. 1993;123:566-8.

8. Kaufer H. Mechanics of the treatment of hip injuries. Clin Orthop. 1980;146:53-61.

9. Haidukewych GJ, Israel TA, Berry DJ. Reverse obliquity fractures of the inter-trochanteric region of the femur. J Bone Joint Surg Am. 2001;83:643-50.

10. Medoff RJ, Maes K. A new device for the fixation of unstable pertrochanteric fractures of the hip. J Bone Joint Surg Am. 1991;73:1192-9.

11. David A, Hüfner K, Lewandrowski KU, Pape D, Muhr G. Dynamische Hüftschraube (DHS) mit Abstützplatte-einesichere Osteo synthesefürhochinstabile "reverse" trochantere Frakturen. Chirurg. 1996;67:1166-73. 
12. Von Hasselbach C, Witzel U. Die Schenkelhalszuggurtungsplatte. Chir Praxis. 1987;38:235-60.

13. Rho JY, Kim SB, Heo YM, Cho SJ, SikChae D, Lee WS. Proximal Femoral Nail Antirotation versus Compression Hip Screw with Trochanter Stabilizing Plate for Unstable Intertrochanteric Hip Fractures. J Korean Fracture Society. 2010;23(2):161-6.

14. Shetty A, Ballal A, Kumar A, Sadasivan, Hedge A. Dynamic Hip Screw with Trochanteric Stablization Plate Fixation of Unstable Inter-Trochanteric Fractures: A Prospective Study of Functional and Radiological Outcomes. J Clin Diagnos Res. 2016;10(9):6-8.

15. Parker MJ, Palmer CR. A new mobility score for predicting mortality after hip fracture. J Bone Joint Surg Br. 1993;75:797-8.

16. Jonnes C, Shishir SM, Najimudeen S. Type II Intertrochanteric Fractures: Proximal Femur. Arch Bone Jt Surg. 2016;4(1):23-8.
17. Matre K, Vinje T, Havelin LI, Gjertsen JE, Furnes $\mathrm{O}$, Espehaug B, et al. Trigen Intertan Intramedullary Nail Versus Sliding Hip Screw. J Bone Joint Surg Am. 2013;95:200-8.

18. Gupta RK, Sangwan K, Kamboj P, Sarabjeet SP, Walecha P. Unstable trochanteric fractures: the role of lateral wall reconstruction. Int Orthop (SICOT). 2010;34:125-9.

19. Bhakat U, Bandyopadhayay R. Comparitive Study between Proximal Femoral Nailing and Dynamic Hip Screw in Intertrochanteric Fracture of Femur. Open J Orthop. 2013;3:291-5.

Cite this article as: Patil SN, Srinivas P. Comparative study between proximal femoral nail and dynamic hip screw with trochanteric stabilizing plate in unstable intertrochantric femur fractures. Int J Res Orthop 2017;3:936-43. 